\title{
DIPLOMA IN THE HISTORY OF MEDICINE
}

The first examinations for the new Diploma in the History of Medicine established by the Society of Apothecaries in 1970 were completed in November and the names of nine successful candidates have now been announced. They are: Jean W. Cuthbert, M.B.,CH.B. (Glasgow), D.P.H.; Sherwin Hall, M.R.C.v.s. ; James Hardman, F.R.C.S.; Phyllis M. Hull, M.Sc.; C.D.T. James, M.R.C.S., L.R.C.P., F.F.A.; H. N. Levitt, O.B.E., L.M.S.S.A., D.P.H.; A. F. Prosser, B.Sc.; M. A. Waugh, M.B., B.S. (Lond.); J. H. Woodward, Ph.D.

All the successful candidates were members of the special diploma course organized by the Society's Faculty of the History of Medicine and Pharmacy and held on Saturdays in the Wellcome Institute. Details of this course, which begins in October each year and runs over three terms, may be obtained from the Faculty's Honorary Secretary, Dr. J. K. Crellin (The Wellcome Institute). Details of the examinations and regulations may be obtained from The Clerk, The Society of Apothecaries, Black Friars Lane, London, V 6EJ.

Those who may be interested are reminded that the Diploma (DHMSA) is an officially approved and registrable qualification.

From 12 to 16 July 1971 a series of seminars will be held on the history of medicine from classical times to the eighteenth century. These seminars are designed for those taking the Diploma course, but a few others may be admitted. Please make early application to Dr. J. K. Crellin.

\section{EIGHTH BRITISH CONGRESS ON THE HISTORY OF MEDICINE LIVERPOOL, 8-11 SEPTEMBER 1971}

The Eighth British Congress on the History of Medicine, organized on behalf of the British Society for the History of Medicine, is to be held in Liverpool from 8 to 11 September 1971. The theme is to be Liverpool's Contributions to Medicine. The Congress President, The Rt. Hon. the Lord Cohen of Birkenhead, and a small local committee have arranged a very attractive programme of scientific sessions, excursions, and social activities. The scientific sessions will be held in the Liverpool Medical Institution, where a special exhibition for the Congress is being arranged, and residents will be accomodated nearby at Rathbone Hall, University of Liverpool.

Full details of the programme and application forms for resident and non-resident membership are available from: The Secretary, Eighth British Congress of the History of Medicine, Wellcome Institute of the History of Medicine, 183 Euston Road, London N.W.1. 